\title{
ANALYSIS OF THE EXPERIMENTAL MEASUREMENT OF ELECTRIC VEHICLE SOUND
}

Dainis Berjoza, Ilmars Dukulis, Inara Jurgena

Latvia University of Life Sciences and Technologies, Latvia

dainis.berjoza@1lu.lv,ilmars.dukulis@1lu.lv,inara.jurgena@1lu.lv

\begin{abstract}
The number of automobiles tends to increase in the world, which leads to an increase in the consumption of fossil fuels. Alternative energy sources are sought for automobiles to reduce environmental pollution. One of the alternative sources of energy for automobiles is electricity. Electric automobiles have many advantages over internal combustion vehicles, and one of them is quiet engine operation. However, using electric automobiles in city traffic can create a lot of situations where quiet vehicles can endanger pedestrians, because pedestrians are accustomed to the sound of conventional vehicles, and electric automobiles might not be noticed by them. The main aim of the present research is to develop a methodology for measuring the sound of an electric automobile and define preconditions for the measurement under specific urban conditions. The research developed a specific methodology for measuring the sound of individual vehicles moving past the microphone, as well as a specific methodology for measuring the sound at various intersections with pedestrian crossings. The test of the methodology in non-urban traffic revealed that the converted Renault Clio generated the highest sound level $-88.6 \mathrm{dBA}$ - at a speed of $90 \mathrm{~km} \cdot \mathrm{h}^{-1}$, whereas the lowest sound level $-71.8 \mathrm{dBA}$ - was recorded at the point closest to the microphone at a speed of $30 \mathrm{~km} \cdot \mathrm{h}^{-1}$. At a distance of $30 \mathrm{~m}$ from the position of the microphone, the sound level decreased to $54.2 \mathrm{dBA}$ at a speed of $30 \mathrm{~km} \cdot \mathrm{h}^{-1}$ and to $67.9 \mathrm{dBA}$ at a speed of 90 $\mathrm{km} \cdot \mathrm{h}^{-1}$. At the next stages, the research intends to analyse the operation of special sound devices and the usefulness of equipping electric vehicles with the devices to improve pedestrian safety.
\end{abstract}

Keywords: electric vehicle, sound, methodology, device, measurement.

\section{Introduction}

Today, one of the kinds of pollution is noise. To reduce the noise of internal combustion vehicles, modern exhaust systems have been developed for the vehicles, while electric and hybrid automobiles generate low noise. When it comes to vehicle noise, usually exhaust noise and engine operation noise are referred to. However, there are other kinds of noise generated by any automobile in motion:

- aerodynamic noise is generated by the air flowing along the automobile, as well as through cabin ventilation and engine cooling vents;

- tyre-road contact noise, depending on the tyre design and road surface;

- transmission and suspension operation noise;

- noise generated by the operation of various auxiliary equipment, such as compressors and other devices.

Usually, the sound generated by an automobile increases with an increase in the speed of the automobile, as well as if the engine runs at high speeds due to a heavy load.

Ambient sound levels in cities increase with an increase in vehicle traffic and vehicle modifications. Quieter vehicles, such as electric or hybrid vehicles, can reduce pedestrians' ability to assess the traffic situation. Electric vehicles could cause safety problems for pedestrians, especially visually impaired pedestrians who rely on vehicle sound as audible signals. For such pedestrians, the primary safety problem arises when electric vehicles move at low speeds [1].

At low speeds, electric vehicles make less sound than vehicles with internal combustion engines do. At high speeds, tyre and wind sounds are the main sources of sound; therefore, the sounds generated by electric vehicles and internal combustion ones are similar. If an electric vehicle performs a low-speed manoeuvre, the collision of it with a pedestrian is 1.38 -fold and with a cyclist 1.33 -fold more probable than that of a vehicle with an internal combustion engine [2].

A research study done in the USA [3] examined various accident factors to identify the relative number of accidents between electric vehicles and pedestrians, as well as between vehicles with internal combustion engines and pedestrians. When slowing down or stopping, or entering or leaving a parking lot, electric vehicles were twice as likely to be involved in accidents as internal combustion ones [3]. 
The research analysed 8387 electric vehicles and 559703 internal combustion ones. In most cases, collisions with pedestrians occurred on road sections with a speed limit of $50 \mathrm{~km} \cdot \mathrm{h}^{-1}$. Of a total of 2609 electric vehicles, 48 or $1.8 \%$ were involved in collisions with pedestrians at a speed of less than $50 \mathrm{~km} \cdot \mathrm{h}^{-1}$. Of a total of 152833 internal combustion vehicles, 1836 or $1.2 \%$ were involved in collisions with pedestrians at the same speed [3]. The research data showed that electric vehicles were, on average, $50 \%$ more often involved in accidents than internal combustion ones were.

A research study done in 16 states of the USA [4] analysed 24297 electric vehicles and 1001100 conventional ones. Totally, 186 electric vehicles were involved in accidents with pedestrians, which was $0.77 \%$ of the total, and 5699 conventional vehicles, or $0.57 \%$ of the total, while 116 electric vehicles or $0.77 \%$ of the total and 3055 conventional vehicles or $0.31 \%$ of the total were involved in accidents with cyclists.

In accordance with the EU Regulation 540/2014, any new hybrid or electric vehicle shall be equipped with an acoustic vehicle alert system from 1 July 2019 onwards. Any hybrid and electric vehicle shall be equipped with an acoustic vehicle alert system until 1 July 2021 [5]. In this way, it is intended to improve the audibility of electric vehicles moving at low speeds.

The acoustic vehicle alert system of an electric or hybrid vehicle must automatically generate a sound within a short radius around the vehicle moving at speeds of up to $20 \mathrm{~km} \cdot \mathrm{h}^{-1}$ when both moving forward and backing up. If the engine of a hybrid vehicle operates, the alert system does not need to operate. If the vehicle is equipped with a back-up alarm, only the alarm must operate when backing up. The alert system has to be a system to be manually deactivated, and it has to generate a continuous sound that gives a signal to pedestrians and other road users. The sound must be similar to that generated by internal combustion engines, and it must vary according to the speed of the vehicle. The sound level of the acoustic system must not exceed the sound level of vehicles with internal combustion engines [5].

The sound generated by electric vehicles has been extensively researched, yet no methodology is available for measuring the sound of internal combustion vehicles and electric ones and assessing the impact on pedestrians in different urban situations. The aim of the research is to develop a research methodology for comparing electric vehicles and internal combustion ones with regard to the sound generated and examining a particular vehicle in urban and non-urban traffic.

\section{Materials and methods}

To measure the sound of passing vehicles, research studies suggest placing a microphone at a distance of two meters from the longitudinal axis of the automobile [6]. The measurements have to be taken at the average height of pedestrians. Taking into account the youngest schoolchildren too, the average human height is approximately $1600-1650 \mathrm{~mm}$. The ears of pedestrians are at a height of $1400-1500 \mathrm{~mm}$. For taking the sound measurements in the present research, the microphone was placed $1450 \mathrm{~mm}$ above the road surface. An analysis of the audibility of sound is required for several standard situations:

- the vehicle moves down a non-urban road, the pedestrian stands on the side of the road and is ready to cross the road;

- the vehicle moves down a straight road in the city, the pedestrian is ready to cross the road at an unregulated or regulated crossing;

- the vehicle moves, making turns at a T-intersection in different directions and crossing a pedestrian crossing;

- the vehicle moves at a cross intersection in different directions and crosses a pedestrian crossing.

It is useful to do sound measurement tests in urban driving both if there are strong background noises and if there are no background noises. The sound measurement test in non-urban driving was carried out at various speeds: $30,50,70$ and $90 \mathrm{~km} \cdot \mathrm{h}^{-1}$.

The sound measurement test in non-urban traffic has to be done on a straight, even and dry road, with an average rolling resistance coefficient of 0.013-0.015. During the test, there has to be no precipitation, and the air temperature has to be at least 100C. Sound-reflecting objects, such as trees, houses and electric poles, have to be at least 10 meters from the road. The road should be light in 
traffic, so that the traffic does not interfere with the test. The wind speed should not exceed 2-3 $\mathrm{ms}^{-1}$. A road section has to be prepared for the test, and a location for the sound level meter has to be selected. The sound level meter is placed on a stand at a height of $1.45 \mathrm{~m}$ above the road surface and at a distance of 2.0 meters from the centre line of the automobile. The measurement zone $-30 \mathrm{~m}$ before and after the sound level meter - is made distantly visible by means of flags 3 and 4 placed by the roadside for a test to be carried out at speeds of 30 and $50 \mathrm{kmh}^{-1}$ (see Figure 1). For a test to be done at speeds of 70 and $90 \mathrm{~km} \mathrm{~h}^{-1}$, the measurement zone is marked by the flags $50 \mathrm{~m}$ before and after the sound level meter. The measurement scheme is shown in Figure 1.

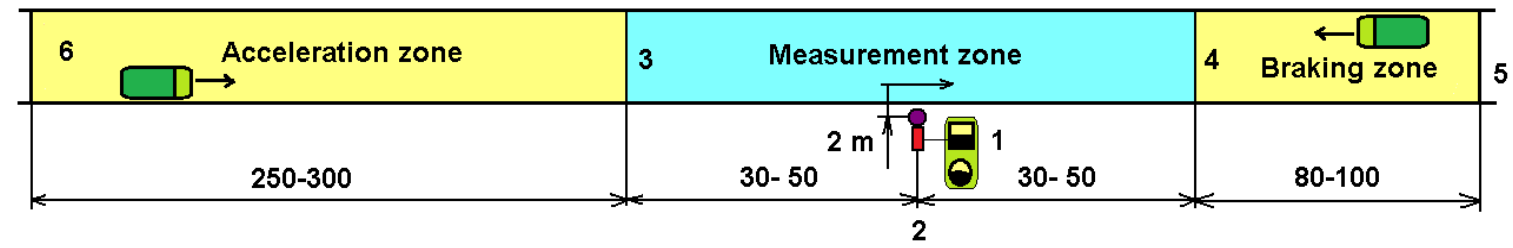

Fig. 1. Measurement scheme for a test in non-urban traffic (metres): 1 - position of the operator with a laptop; 2 - microphone; 3 - measurement start mark; 4 - measurement finish mark;

$$
5,6-\text { automobile turning points }
$$

To be able to carry out the test on the right side of the road, the test is done in one direction only. An Extech HD600 sound level meter or another similar measuring device has to be used to measure the sound. The device has to be set to the highest resolution mode for data recording at least 10 times per second.

Two operators participate in the test. One operates the sound level meter at measurement point 1 , while the other drives the automobile. The automobile is accelerated in the acceleration zone, approximately $300-350 \mathrm{~m}$ from the radar position. The automobile achieves the speed required before entering measurement zone 3 according to a Holux GPS logger or other similar speed measuring device. The accuracy required to maintain the speed desired is $\pm 2 \mathrm{~km} \cdot \mathrm{h}^{-1}$. When entering measurement zone 3 , the automobile operator pushes the horn button to make an audible signal. In this way, the sound level meter receives the measurement start signal. When leaving the measurement zone at point 4 , the automobile operator pushes the horn button again. In this way, the sound level meter records the start and finish points of the measurement zone. After the test, the data of the sound level meter are saved in Microsoft Excel format.

The test could also be done without making an audible signal, yet in this case it is necessary to take into account the speed of movement of the automobile and calculate the distance travelled at a particular speed and the number of data points logged by the sound level meter. For example, if the speed is $50 \mathrm{~km} \cdot \mathrm{h}^{-1}$, the automobile travels $13.89 \mathrm{~m}$ per second. After the test, the data logging frequency is taken into account in processing the measurement data. For example, if the data logging frequency is $0.1 \mathrm{~s}$, during this period the automobile travels 1.389 meters at a speed of $13.89 \mathrm{~m} \cdot \mathrm{s}^{-1}$. Accordingly, the measurement zone before the sound level meter ( 30 meters) is represented by 22 data points. The movement of the automobile after passing the microphone and leaving the measurement zone at point 4 is also represented by 22 data points. The test should have five replications, and three measurements yielding the most coherent data have to be selected for data processing.

The measurement methodology could be tested on internal combustion and electric vehicles. A converted RENAULT Clio with a maximum engine power of $50 \mathrm{~kW}$, Barum 175/65 R14 82T tyres, a maximum speed of $120 \mathrm{kmh}^{-1}$ and a range of $65 \mathrm{~km}$ per charge was exploited in the test.

The test employed an Extech HD600 sound level meter (see Figure 2).

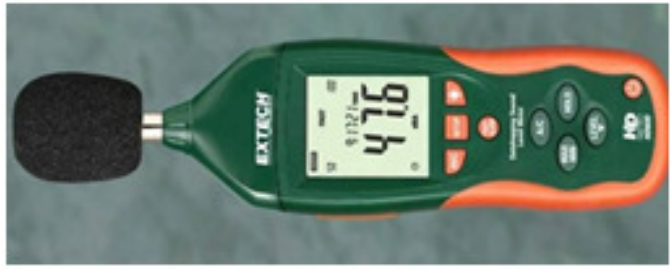

Fig. 2. Extech HD600 sound level meter 
The sound level meter can store data both in its internal memory and in a computer with a special software application. The results of the measurements could be viewed graphically on a computer (see Figure 3). The graph shows the data capture points and the stages of audible signal activation. The main disadvantage of the methodology with audible signal activation is the response time of the automobile operator when entering and leaving the measurement zone. Figure 3 shows fast increases in the noise level at the start and finish of the measurements when the audible signal was activated.

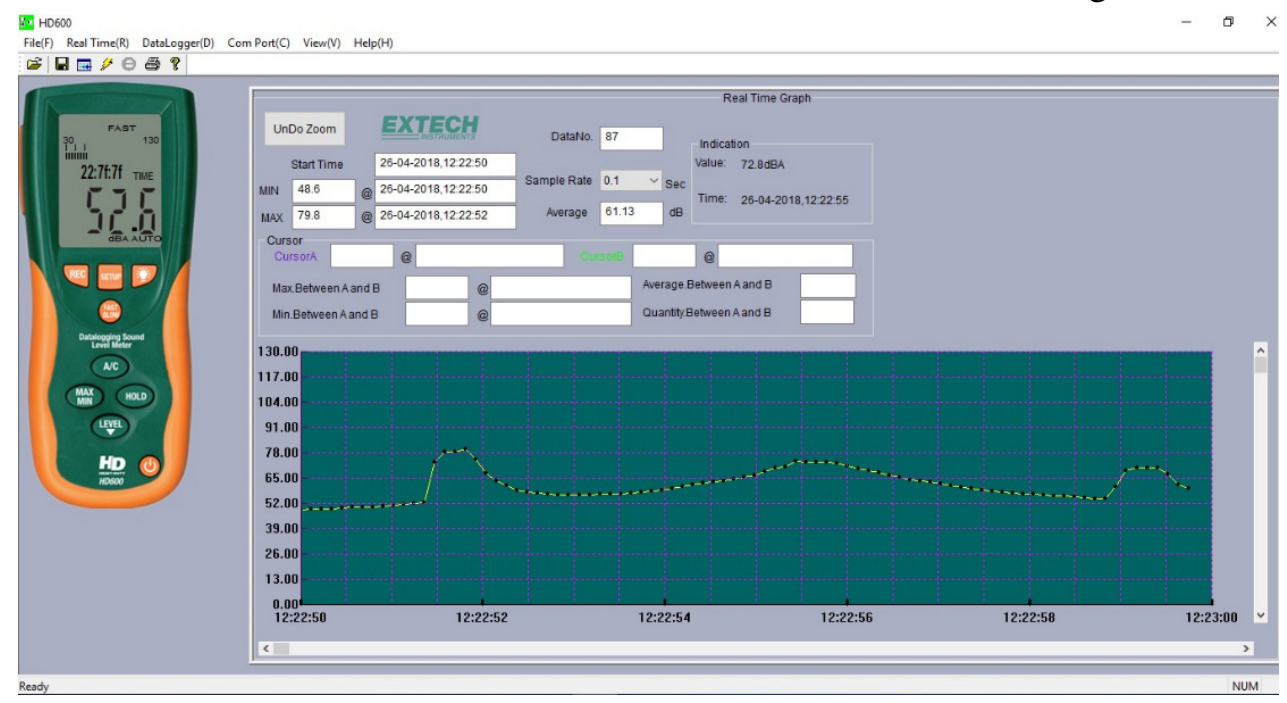

Fig. 3. Screenshot of the application window for the sound level meter

Key technical parameters of the Extech HD600 sound level meter:

- Range: 30-130dB;

- Basic Accuracy: $\pm 1.4 \mathrm{~dB}$;

- Weighting: A\& C;

- Response Time: Fast/Slow;

- PC Interface: USB;

- Datalogging: 20000 Records;

- Weight: $350 \mathrm{~g}$.

A data logger Holux GPS Sport 245, which is attached to the steering wheel of the test automobile, has to be used for maintaining precise speed.

Preparation for testing the measurement methodology is shown in Figure 4. A rectangle marked on the road surface with chalk at a distance of $2 \mathrm{~m}$ from the microphone of the sound level meter serves as a guide for the movement of the automobile.

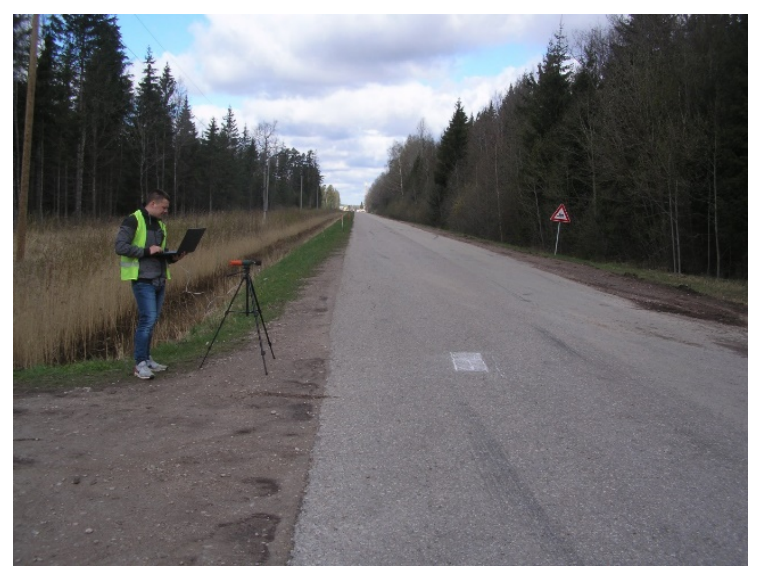

Fig. 4. Road section for the test

If other sound sources appear closer than $150 \mathrm{~m}$ from the sound level meter during the test, the measurement is rejected and repeated. 
The sound measurement test in urban traffic has to be done on a straight road at a speed of 40$50 \mathrm{~km} \cdot \mathrm{h}^{-1}$. At a T-intersection and a cross intersection, the test automobile is driven according to the driving conditions, at a speed of speed of $15-35 \mathrm{~km} \cdot \mathrm{h}^{-1}$. The movement of the electric automobile at a T-intersection and a cross intersection, which could affect the safety of pedestrians, is analogous, only the background noises could differ; therefore, some tests having no background noises are carried out only at one kind of intersection, e.g. at a cross intersection.

The test is usually performed in two kinds of settings: the electric automobile is the only one at the intersection; and there is background noise from other vehicles. Due to the fact that such tests with background noise from other vehicles involve a large number of occasional factors, the test is replicated at least 10 times and only the average values are used in data processing. When carrying out a test individually for one vehicle, the test is done either at night, when there is very little traffic in the city, or on a testing ground, marking the contours of an intersection on the ground.

The test is carried out by two operators. One operates the radar, while the other drives the automobile. The test is done with three types of automobiles: electric, conventional (diesel) and conventional (petrol). It is advised to choose automobiles with diesel engines and Otto engines of the same size class as electric ones. In any case, it is assumed that the electric automobile has stopped at an intersection or slowly approaches the intersection. The sound level meter is activated when the electric automobile is 1-10 meters from the stop line, depending on the driving conditions.

Carrying out the test at a cross intersection (see Figure 5), the sound level meter is placed in positions 1 and 2 at pedestrian crossings 8 , through which pedestrian movement is permitted under the appropriate conditions. The test electric automobile moves along route 5 at the first stage of the test (sound is measured at position 1). In the second case, the electric automobile moves along route 6, yet the sound is measured at position 2. It is also important to measure the sound of electric automobiles at pedestrian crossings near the centre line dividing the road; however, in case of heavy traffic it is not safe to take measurements in this area. Any measurement is performed until the moment the automobile is 5-8 meters away from the measurement position (depending on an automobile following the test automobile).

a)

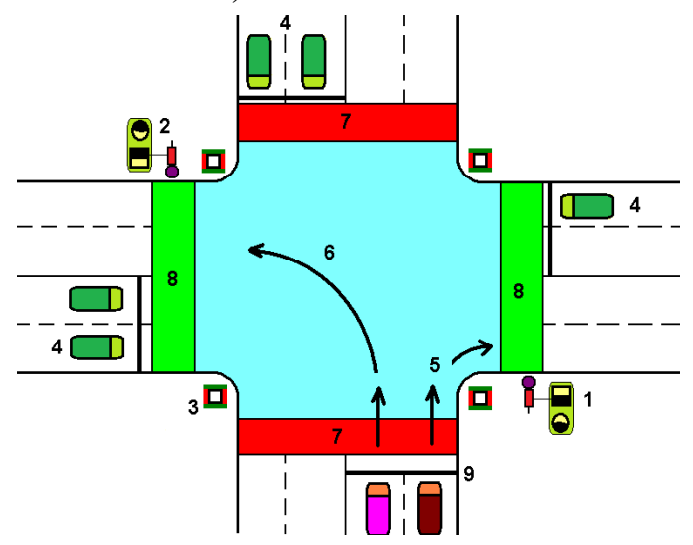

b)

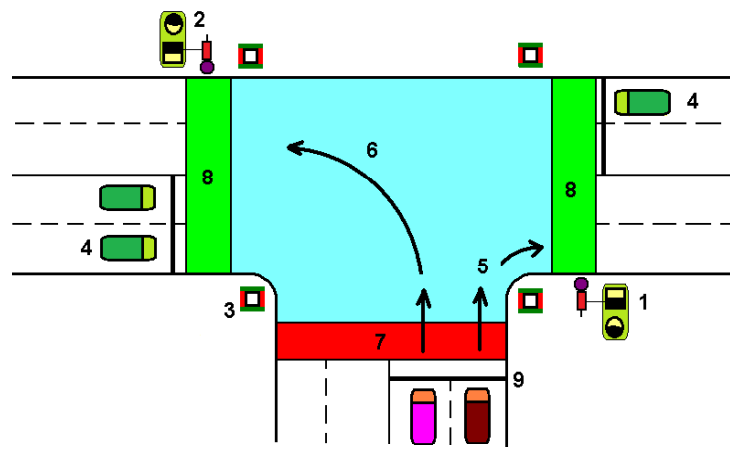

Fig. 5. Sound measurement in urban traffic - cross intersection (a); T-intersection (b):

1, 2 - positions of the sound-measuring operator; 3 - traffic light; 4 -internal combustion vehicles generating background noise (randomly located); 5 - test route for taking measurements at position 1;

6- test route for taking measurements at position 2; 7 - pedestrian crossings where pedestrian

movement is not permitted during the movement of the electric vehicle; 8 - pedestrian crossings where pedestrian movement is permitted during the movement of the electric vehicle; 9 - stop line for the start of measurements

In principle, pedestrians must not walk when the test is done on a regulated pedestrian crossing in urban conditions, because if there is a green traffic light for vehicles, pedestrians have a red light (see Figure 6). The measurements are more important in cases where the pedestrian crossing is unregulated or a flashing yellow signal is lit at the traffic light. The test electric automobile travels at a speed of $40-50 \mathrm{~km} \cdot \mathrm{h}^{-1}$. The sound level meter is activated at least $60 \mathrm{~m}$ before position 2 . The data recorded at a distance of $50 \mathrm{~m}$ from the sound level meter are processed according to the methodology described above. The sound level meter is switched off when the test automobile is at a distance of 10-15 m from 
measurement position 2 or 6 . In the present test, it was useful to use two sound level meters, or one sound level meter and two microphones for synchronously recording the data at measurement positions 2 and 6.

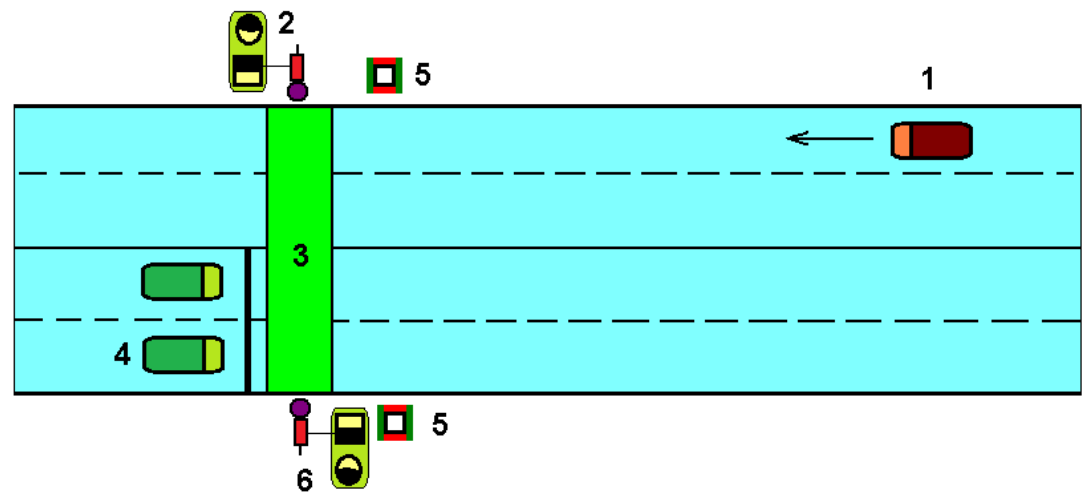

Fig. 6. Sound measurement at a pedestrian crossing in urban traffic: 1 - test automobile;

2, 6 - measurement positions; 3 - pedestrian crossing; 4 - vehicles generating background noise; 5 - traffic light

The methodology has to be tested and corrected after it has been developed. Due to the limited scope of the present paper, the authors are going to analyse the methodology for tests in non-urban traffic only.

\section{Results and discussion}

The authors tested the methodology after it was developed. Due to the limited scope of the present paper, the authors analysed the methodology for tests in non-urban traffic only. The start and finish times of data logging in the series of test replications were recorded by means of an audible signal, yet during data processing the data were erased and not used for representation and analysis. The highest noise level was recorded when the automobile passed the microphone. In all test replications, the data were recorded at a distance of $30 \mathrm{~m}$ before and after the microphone. The average data for a speed of $30 \mathrm{~km} \cdot \mathrm{h}^{-1}$ are shown in Figure 7.

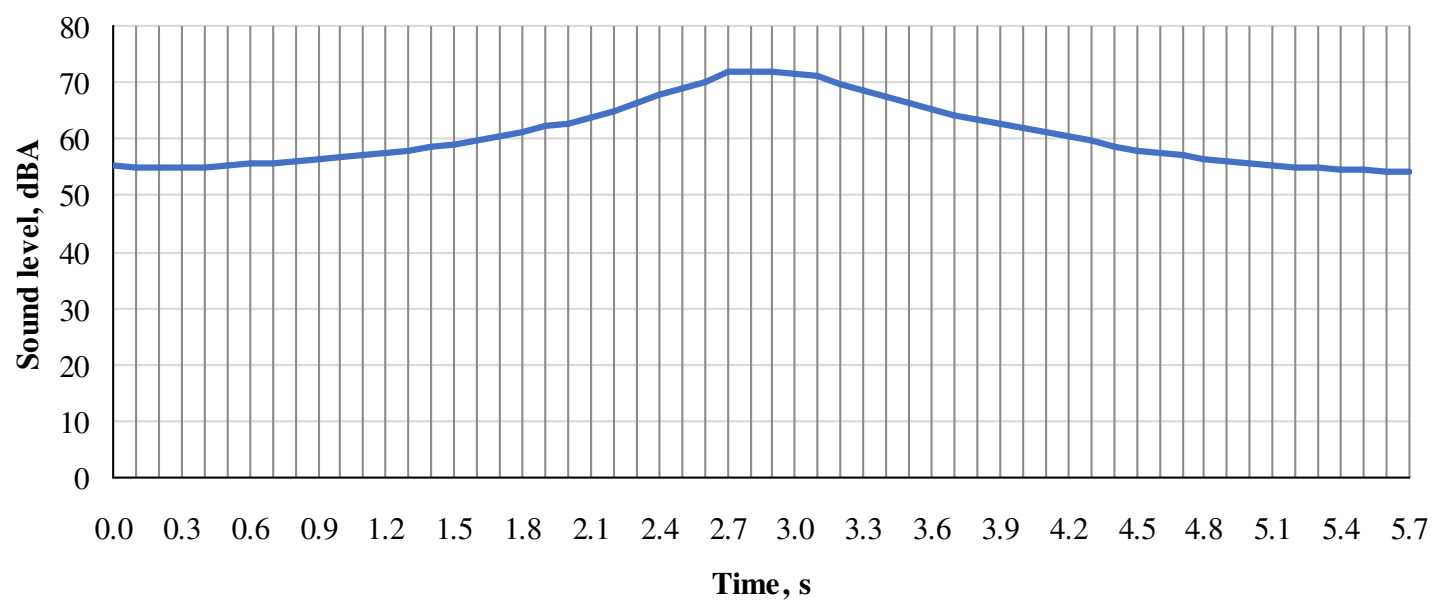

Fig. 7. Change in the noise level for the Renault Clio EV travelling at a speed of $30 \mathrm{kmh}^{-1}$

Since the speed of movement of the automobile is known, which was constant during the test replications, it is also possible to identify the distance of the automobile from the location of the microphone and place the distance, measured in meters, on the abscissa axis. At the final stage of the measurements, the noise level was $2 \%$ lower after 5.6 seconds, which could be explained by the fact that the motor and transmission were located in the front part of the automobile. Mathematical data processing yielded a correlation coefficient in the range from 0.986 to $0.997 \%$, which indicated a high level of correlation for the test replications (values between 0.7 and $1.0(-0.7$ and -1.0$)$ indicate a strong positive (negative) linear relationship via a firm linear rule).

The test data for the Renault Clio driven at a speed of $50 \mathrm{~km} \cdot \mathrm{h}^{-1}$ are shown in Figure 8. 


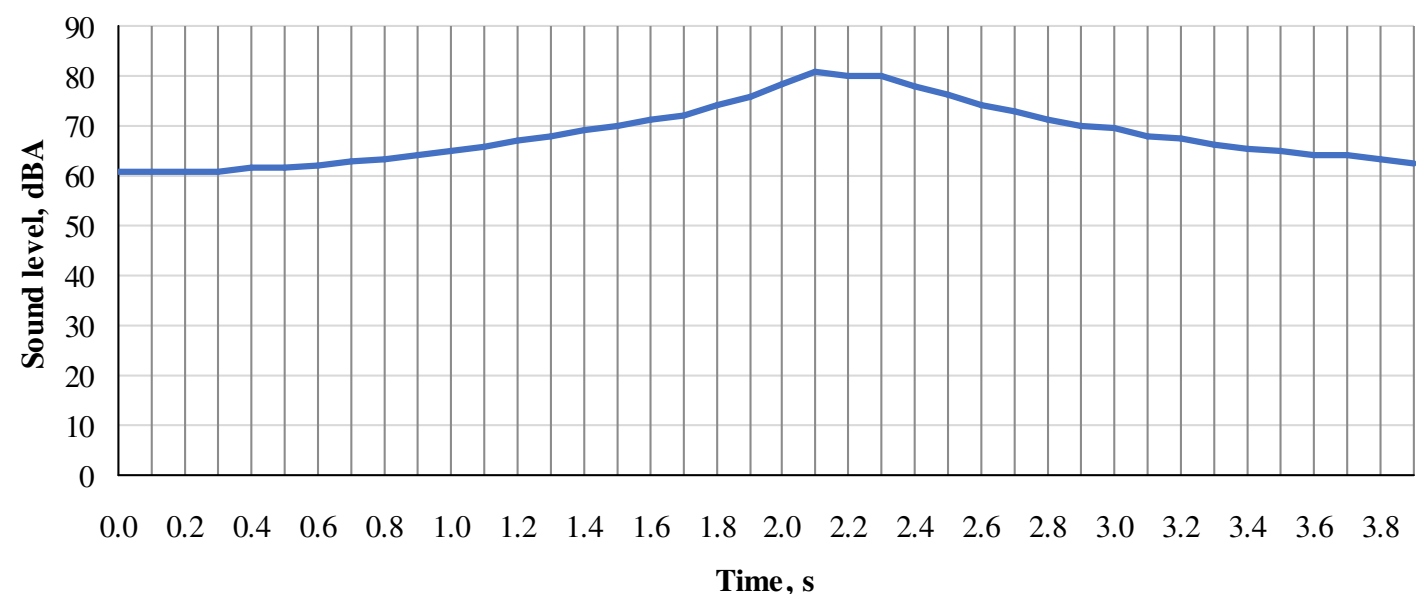

Fig. 8. Change in the noise level for the Renault Clio EV travelling at a speed of $50 \mathbf{~ k m h}^{\mathbf{- 1}}$

The graph shows that the automobile reached the microphone after $2.1 \mathrm{~s}$. At a speed of $50 \mathrm{~km} \cdot \mathrm{h}^{-1}$, the automobile travelled $29.2 \mathrm{~m}$ during this period, which was accurate enough to comply with the methodology (the audible signal had already stopped working at that moment). However, when leaving the test zone, the automobile operator made the signal too early, and the automobile had travelled only 23.6 meters during that period, which significantly did not comply with the test methodology. In addition, making the signal too early was observed for all the test replications. In principle, a receding noise source was not as important as an approaching noise source with regard to traffic safety. Mathematical data processing yielded a correlation coefficient in the range from 0.973 to 0.995 , which indicated a high accuracy of the measurements and a strong correlation.

The results of the measurements made during the five test replications at $90 \mathrm{~km} \cdot \mathrm{h}^{-1}$ are summarized in Figure 9. At such speed of movement, it was very difficult for the operator sitting in the automobile to accurately make a signal, as the automobile travelled $25 \mathrm{~m}$ per second and the whole measurement took slightly less than $3 \mathrm{~s}$. In this case, too, the automobile reached the microphone after 1.5 seconds, covering a distance of 37.5 meters. Consequently, the signal was made too early. When leaving the measurement zone, the signal was made after covering a distance of $35 \mathrm{~m}$, i.e. too late.

Analysing all the cases and unprocessed data of the test allows concluding that for accurate distance identification it is useful to correct the data series based on the distance travelled instead of employing the method of "pushing the automobile horn button to make a signal" at the start and finish of a measurement. Mathematical data processing yielded a correlation coefficient in the range from 0.837 to 0.993 , which indicated a strong correlation among the measurements. A weaker correlation than that in the measurements at lower speeds was obtained owing to the response time of the automobile operator at higher driving speeds and a relatively shorter measurement period, which was only 3 seconds. In a similar way, it is necessary to test the methodology for urban traffic, which is planned to be done at the next research stages.

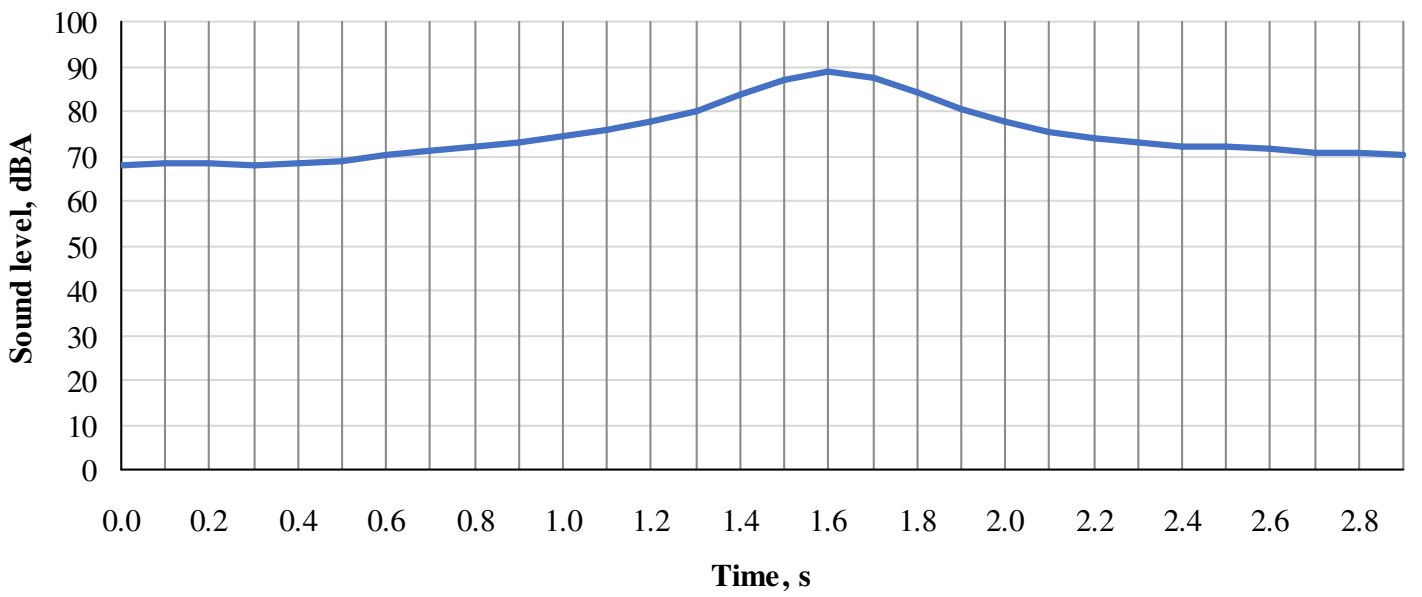

Fig. 9. Change in the noise level for the Renault Clio EV travelling at a speed of $90 \mathbf{k m h}^{-1}$ 


\section{Conclusions}

1. In accordance with the EU legislation, newly manufactured electric vehicles shall be equipped with noise-emitting devices that ensure the safety of pedestrians when driving at low speeds. For this reason, it is necessary to develop and test a methodology for measuring electric vehicle sound in urban and non-urban traffic, which is adapted for the conditions in Latvia.

2. A sound measurement methodology for performing comparisons of electric and hybrid automobiles with conventional ones of a similar class in terms of sound generated has been developed and analysed.

3. The methodology developed allows for measurement of the noise generated by vehicles driven at different speeds in non-urban traffic, as well as of noise levels in the city.

4. Under urban traffic conditions, it is recommended to conduct sound measurement experiments with background noise, increasing the number of replications to at least 10. For comparison, it is also important to measure the sound without background noise.

5. The methodology for measuring noise in non-urban traffic was tested on a converted Renault Clio. Starting and finishing measurements by means of the automobile horn signal leads to accurate results only at low speeds, yet at speeds exceeding $40 \mathrm{~km} \cdot \mathrm{h}^{-1}$ it results in inaccuracies, as the measurements are started and finished inaccurately.

6. At a speed of $30 \mathrm{~km} \cdot \mathrm{h}^{-1}$ in non-urban traffic, the converted Renault Clio generated a sound level of $71.8 \mathrm{dBA}$, at a speed of $50 \mathrm{~km} \cdot \mathrm{h}^{-1}$ the sound level increased to $80.9 \mathrm{dBA}$, while at a speed of 90 $\mathrm{km} \cdot \mathrm{h}^{-1}$ the sound level was equal to $88.6 \mathrm{dBA}$.

7. In non-urban traffic, the lowest sound levels in the measurement zone were recorded at the furthest distance, i.e. at $30 \mathrm{~m}$ from the position of the microphone. At a speed of $30 \mathrm{~km} \cdot \mathrm{h}^{-1}$, the sound level reached $54.2 \mathrm{dBA}$, while at the speeds of 50 and $90 \mathrm{~km} \cdot \mathrm{h}^{-1}$, the sound levels were 60.8 and $67.9 \mathrm{dBA}$, respectively.

8. The method of logging data points based on the average movement period in the measurement zone is considered to be more accurate. Having known the measurement period based on the data points logged by the sound level meter with an accuracy of $0.1 \mathrm{~s}$, it is possible to determine the number of data points logged for the particular road section. In this case, preparation for the measurement stage is also facilitated, as it is not necessary to place start and finish marks in the measurement zone.

\section{References}

[1] Hastings A., Pollard J. K., Garay - Vega L. etc. Quieter cars and the safety of blind pedestrians, phase 2, Development of Potential Specifications for Vehicle Countermeasure Sounds. National Highway Traffic safety Administration. DOT HS 811 496, 2011, 156 p.

[2] Bonanti C. J. Minimum sound requirements for hybrid and electric vehicles. National Highway Traffic Safety Administration, 49 CFR Part 571, Docket No. NHTSA-2011-0148, RIN 2127AK93, Federal Motor Vehicle Safety Standards, 2011, 248 p.

[3] Hanna R. Incidence of pedestrian and bicyclist crashes by hybrid electric passenger vehicles. National Highway Traffic safety Administration. Technical Report. DOT HS - 811 204, 2009, $22 \mathrm{p}$.

[4] Wu J., Austin R., Chen L. Incidence rates of pedestrian and bicyclist crashes by hybrid electric passenger vehicles: An update (DOT HS 811 526). Washington, DC: National Highway Traffic Safety Administration, 2011, 32 p.

[5] Par mehānisko transportlīdzekḷu skaņas līmeni un rezerves trokšņa slāpēšanas sistēmām: Eiropas parlamenta un padomes regula.( Regulation (EU) No 540/2014 of the European Parliament and of the Council of 16 April 2014 on the sound level of motor vehicles and of replacement silencing systems, and amending) Eiropas Savienības Oficiālais Vēstnesis. ES Nr. 540/2014, L 158/131 - L 158-195 (In Latvian)

[6] Tabata T., Konet H., Kanuma T. Development of Nissan Approaching Vehicle Sound for Pedestrians. Paper Number 11- 0097, pp. 1-6, [online] [25.02.2020]. Available at: https://wwwesv.nhtsa.dot.gov/Proceedings/22/files/22ESV-000097.pdf 